\section{(6) OPEN ACCESS}

\title{
Places and people: the perceptions of men who have sex with men concerning STI testing: a qualitative study
}

\author{
Jessica Datta, ${ }^{1}$ David Reid, ${ }^{1}$ Gwenda Hughes, ${ }^{2}$ Catherine H Mercer, ${ }^{3}$ Sonali Wayal, ${ }^{3}$ \\ Peter Weatherburn ${ }^{1}$
}

${ }^{1}$ Department of Social and Environmental Health Research, London School of Hygiene \& Tropical Medicine, London, UK ${ }^{2}$ Centre for Infectious Disease Surveillance and Control, Public Health England, London, UK ${ }^{3}$ Department of Infection and Population Health, University College London, London, UK

\section{Correspondence to}

Peter Weatherburn, Sigma Research, Department of Social and Environmental Health Research, London School of Hygiene \& Tropical Medicine, 15-17 Tavistock Place, London, WC1H 9SH, UK; peter. weatherburn@Ishtm.ac.uk

Received 16 November 2016 Revised 26 June 2017 Accepted 2 July 2017 Published Online First 4 August 2017
CrossMark

$$
\begin{aligned}
& \text { To cite: Datta J, } \\
& \text { Reid D, Hughes G, } \\
& \text { et al. Sex Transm Infect }
\end{aligned}
$$$$
\text { 2018;94:46-50. }
$$

\section{ABSTRACT}

Objectives To explore the experiences and views of men who have sex with men (MSM) on attending clinical sexual health services and their preferences regarding service characteristics in the context of the disproportionate burden of STIs experienced by this group. The wider study aim was to develop a risk assessment tool for use in sexual health clinics. Methods Qualitative study comprising eight focus group discussions with 61 MSM in four English cities. Topics included: experience of attending sexual health services, perceptions of norms of attendance among MSM, knowledge of, and attitudes towards, STIs and views on 'being researched.' Discussions were audiorecorded and transcribed and a thematic data analysis conducted.

Results Attending sexual health services for STI testing was described as embarrassing by some and some clinic procedures were thought to compromise confidentiality. Young men seeking STI testing were particularly sensitive to feelings of awkwardness and self-consciousness. Black and ethnic minority men were concerned about being exposed in their communities. The personal qualities of staff were seen as key features of sexual health services. Participants wanted staff to be friendly, professional, discreet, knowledgeable and non-judgemental. Conclusions A range of opinion on the type of STI service men preferred was expressed with some favouring generic sexual and reproductive health clinics and others favouring specialist community-based services. There was consensus on the qualities they would like to see in healthcare staff. The knowledge, conduct and demeanour of staff could exacerbate or ameliorate unease associated with attending for STI testing.

\section{INTRODUCTION}

The provision of accessible, high-quality sexual health services is acknowledged as key to improving sexual health outcomes. ${ }^{1}$ Services for testing and treating STIs in the UK are free of charge, open access and offer anonymity to users in a diverse range of settings. These include general practice, specialist genito-urinary medicine (GUM) and sexual and reproductive health clinics, community-based services and, increasingly, self-sampling services. There have been calls to ensure that services meet the needs of men who have sex with men $(\mathrm{MSM})^{2}$ who experience a disproportionate burden of STIs. ${ }^{3}$

In line with recommendations, ${ }^{4}$ there is evidence of an increase in HIV and STI testing among MSM in England. ${ }^{5}$ However, a number of factors may influence uptake. ${ }^{6-10}$ Negative societal stereotyping of homosexuality and the 'deviancy and social undesirability' 11 associated with STIs may deter MSM from accessing sexual health services. ${ }^{12}$ The 'discredited setting' of a sexual health clinic may discourage attendance ${ }^{13}$ as may the fear of being identified in such settings. ${ }^{14}$ Unequal power relations between professionals and patients present in clinic settings may also act as a disincentive to attendance, particularly for young men, ${ }^{15} 16$ and these may be mitigated or exacerbated by the conduct of staff. ${ }^{1117}$

Little research describes the views and preferences of MSM regarding STI testing or sexual health services and this study offers new insights. Drawing on data from eight focus group discussions (FGDs) with MSM in four English cities, we report on participants' experiences of STI clinic attendance, one of the four topics covered in discussions, and, in particular, on the sociospatial and interpersonal aspects of services. We refer mainly to GUM clinics, which were most commonly used by participants, but also to sexual and reproductive health clinics, community-based STI services, primary care and other hospital-based services.

The primary aim of the study was to inform the formulation of questions and data collection procedures for the development of a risk assessment tool for use in sexual health clinics. The proposed tool will link routinely collected demographic and biomedical data with purposively collected information about service users' risk behaviour in order to strengthen the evidence base with which to inform the development of tailored risk-reduction interventions.

\section{METHODS \\ Sampling and recruitment}

Men were recruited via gay community organisations, which included study information in their newsletters and/or Facebook pages, and a geospatial sociosexual networking application aimed at MSM. Interested men were invited to complete a short online questionnaire via a web link in order to 
assess whether they met eligibility criteria (ie, aged 16 or older, identify as male or transmale, ever had sex with a man and sexually attracted to men) and to enable purposive sampling.

A sample was recruited to reflect a range of personal characteristics and experience of sexual health services including age, ethnicity, sexual identity, STI testing history, previous STI diagnosis and HIV status at most recent test. Research cities have large numbers of MSM accessing local GUM clinics and diverse STI testing infrastructure.

\section{Focus group organisation}

A maximum of 10 men were invited to participate in each group. Two were held at London School of Hygiene \& Tropical Medicine in London and two each at the premises of LGBT (lesbian, gay, bisexual, transgender) organisations in Birmingham, Leeds and Manchester. Participants were each given $£ 40$ for their participation. Information about the study was provided and questions answered. All gave written consent to participate.

\section{Topic guide}

The research team developed a focus group guide covering four topics: experience of sexual health services; perceptions of norms of attendance among MSM; knowledge of, and attitudes towards, STIs; and views on 'being researched' in sexual health clinics. FGDs ran for $90 \mathrm{~min}$ with each topic lasting around 20-25 $\mathrm{min}$.

\section{Data analysis}

FGDs were audio-recorded and transcribed by transcribers who as far as possible identified individuals by voice and assigned each a code number. JD open coded the data from the first topic discussed, categorised the codes and identified themes, noting divergent views. PW and DR read the transcripts and cross-checked the coding frame with themes. Interpretation of data is based on analysis of each FGD rather than of individual accounts.

\section{RESULTS}

A total of 330 individuals accessed the web link of whom 133 completed the survey. Three were excluded as ineligible. Of the 130 that we attempted to contact by telephone or email, 70 were recruited to attend a group. Others were uncontactable or excluded because groups had reached capacity. Sixty-one men participated (table 1) and nine more were invited but did not attend. FGDs took place in July and August 2015.

A range of factors for choosing or rejecting a particular sexual health service for STI testing were highlighted in the FGDs including barriers such as location, opening hours, appointment arrangements and waiting times. In discussion, participants emphasised both the 'place' of sexual health services and interaction with staff. This paper explores these aspects of attending sexual health services for MSM and how they may influence satisfaction.

\section{Attending a sexual health clinic}

Men described two motivations for attending a sexual health clinic: concern that they had acquired an infection (whether symptomatic or not) or as part of a regime of regular check-ups to safeguard their own and their partners' sexual health. These motivations, particularly the first, were marked by some anxiety about the outcome of tests and what treatment might involve. As well as worries about undergoing tests, participants talked about

\begin{tabular}{|c|c|}
\hline \multicolumn{2}{|l|}{ Age } \\
\hline $20-29$ & 22 \\
\hline $30-39$ & 21 \\
\hline $40-49$ & 11 \\
\hline 50 and over & 7 \\
\hline \multicolumn{2}{|l|}{ Ethnic group } \\
\hline White & 40 \\
\hline Black & 7 \\
\hline Asian & 12 \\
\hline Mixed heritage & 2 \\
\hline \multicolumn{2}{|l|}{ Sexual identity } \\
\hline Gay/Queer & 55 \\
\hline Bisexual & 3 \\
\hline Does not use term & 3 \\
\hline \multicolumn{2}{|c|}{ Recency of STI clinic attendance } \\
\hline In the last year & 46 \\
\hline In the last 5 years & 10 \\
\hline Never & 5 \\
\hline \multicolumn{2}{|l|}{ Ever diagnosed of STI } \\
\hline Yes & 33 \\
\hline No & 28 \\
\hline \multicolumn{2}{|c|}{ HIV status at most recent test } \\
\hline Positive & 11 \\
\hline Negative & 50 \\
\hline \multicolumn{2}{|c|}{ Focus group discussion numbers } \\
\hline London 1 & 7 \\
\hline London 2 & 10 \\
\hline Leeds 1 & 7 \\
\hline Leeds 2 & 9 \\
\hline Manchester 1 & 6 \\
\hline Manchester 2 & 5 \\
\hline Birmingham 1 & 9 \\
\hline Birmingham 2 & 8 \\
\hline
\end{tabular}

the stigma associated with both having sex with men and being thought to be infected with an STI.

Young men in particular were uncomfortable about disclosure of their sexual identity and discussing their behaviour in an unfamiliar environment. Recalling their own early experiences, many participants talked about their apprehension at first attending a sexual health clinic in their teens or 20 s when they were sexually inexperienced, less confident about their sexual identities and new to accessing health services. One man remembered being 'absolutely terrified' having never talked about his sexuality to anyone before. Participants shared accounts of travelling far from home so as not to be recognised entering a clinic and talked about the social risks of being identified as gay or bisexual in a small town where people known to you might work in local health services. Black and Asian participants were particularly aware that they might be identified in their communities and the potential for public censure because of homophobic attitudes.

...because it's a very small Asian community. I know that things get around a lot and... I think because he [doctor] was Asian, I think he knew my family and... he just went on this massive lecture... and it was just like, 'Are you still praying?' and this and that and I thought that was really not on. (age 20, London, HIV negative)

I think one of my fears is the fear of seeing another black person taking care of me there. I think I prefer to be treated by a white person than a black. Simply because, I don't know-I think it's a 
matter of trust. I think: 'What if this black person maybe knows someone that I know'? (age 44, Birmingham, HIV negative)

We found little variation in the experiences of men in different cities except that larger cities offer more choice of services and that safeguarding anonymity is more difficult in small towns.

\section{Material and social aspects of space}

Clinic location, the material environment and the human interactions shaping the physical space were discussed by participants. The approach to a clinic and its entrance from the street could be off putting to some if they felt that entering would draw attention to them and to their reasons for attendance. Whether a clinic was located 'slap bang in the middle of town' or on the periphery of a hospital site, participants said they could feel self-conscious about being seen to go in.

So sometimes it can feel like the walk of shame itself, to get to the clinic. (age 39, Birmingham, HIV negative)

Once inside, the physical layout of the space could be more or less conducive to personal comfort. An open waiting room might result in awkward social encounters with ex-partners, colleagues or acquaintances. Publicly enacted procedures such as those for booking in or being called by name 'at the top of their voice' for a consultation could compromise individuals' confidentiality. A man who is HIV positive expressed anxiety about his status being widely known and how, in some clinics, it might be deduced.

[The HIV unit] was a separate door where people would come out and call people in. So you'd know anybody called who went through that door was HIV positive. (age 29, Birmingham, HIV positive)

Some men reported continuing to attend a familiar clinic even though it was no longer the most convenient geographically. Having familiarised themselves with navigating that clinic's procedures, they wanted to avoid the potential discomfort of locating and entering a different one.

There was no overwhelming preference expressed for a specific type of service and participants reported differing preferences regarding clinic space and the configuration of services. One man, for example, liked the contemporary 'boutique hotel' style décor of a London service while others reported feeling more at ease attending the more neutral environment of a clinic providing services to a wider clientele because of the potential for greater anonymity. In contrast, one participant explained that, as a gay man, he had felt out of place in a generic clinic.

[(It]) was just full of like young girls, getting the pill, and me so it was a bit weird... (age 37, London, HIV negative)

Men described feeling discomfort waiting for an appointment in a non-specialist setting such as a retail pharmacy which hosted a sexual health clinic or a general hospital's phlebotomy department. In the former, they felt exposed waiting in a public space, unsure where to stand. In the latter, they were obliged to draw attention to themselves explaining to staff that they were presenting for sexual health testing while others were 'there just to have their cholesterol checked.'

\section{Interaction with staff}

Staff qualities

The personal qualities of clinic staff were seen as key features of services. Participants wanted members of staff to be friendlybut not too friendly-professional, discreet and knowledgeable, and, most of all, not to be seen to judge them or their sexual lifestyles. Staff members' demeanour and behaviour could make the difference between clinic attendance being an awkward experience to one that was reasonably pleasant.

I think the staff are the thing that make a clinic... their attitude towards you, their professionalism, their knowledge base. Basically everything. (age 44, London, HIV positive)

Participants were highly sensitive to staff attitudes and how they thought staff perceived them and their sexual behaviour. Some admitted that they felt susceptible to implied criticism even though members of staff were not displaying any explicitly censorious behaviour. Their experience of clinic consultations could be awkward or even distressing and, if they knew they had put themselves at risk of infection, they might be self-critical and therefore compound their own discomfort.

\section{I think if you are going into a clinic you are feeling quite vulnerable anyway... so... the staff need generally to be ultra-sensitive to what you need and kind of talk you through the experience. (age 28, London, HIV negative)}

Individuals gave examples of unpleasant interactions with healthcare staff and these were more likely to have occurred when they were younger and less confident. One man reported having endured 'about a quarter of an hour finger wagging lecture about how I should mend my ways' at a GUM clinic. Another thought that, although staff were likely to be told not to judge clinic users, 'they kind of do. You can just see it in their faces.' Participants expressed strong feelings about being asked about numbers of sexual partners during consultations. Whether or not they understood the purpose of the question, some felt that it was intrinsically judgemental of their behaviour.

\section{Staff expertise}

The expertise of clinic staff and the availability of comprehensive services were highly valued by participants. Some men were well informed about the risks associated with particular sexual practices and how to mitigate them. They wanted staff to be aware of the latest research and to advise them from an evidence-based perspective.

Some reported a preference for attending services-usually provided by community organisations-which specialised in working with MSM although this preference was not universal. Those who chose to use these services valued staff who they felt understood and perhaps shared their lifestyles and sexual behaviour.

I think it makes a difference when you know that the person who's testing you is gay. You don't feel like you're having to educate [them]... Whereas with GUM sometimes you're kind of explaining to people what you're doing in your personal life. (age 24, Leeds, HIV negative)

Men diagnosed with HIV did not report markedly different experiences of STI testing or treatment than other men. One reported appreciating the continuity of care he received, having developed a trusting relationship with his consultant.

\section{DISCUSSION}

The paper outlines the views expressed by 61 MSM who participated in one of eight FGDs conducted in four English cities on attending for STI testing. The experience of attending STI testing premises was described as embarrassing by some, especially by young, inexperienced men, and this discomfort could be exacerbated or ameliorated by clinic procedures and staff attitudes. A range of opinion on the type of services men preferred 
was expressed but there was broad consensus on the qualities they would like to see in healthcare staff.

This study is novel in describing the views of MSM about accessing STI services and was valuable for developing a risk assessment tool for use in sexual health services. However, participants were self-selected and findings may not be generalisable to all MSM.

STIs—and the places where they are treated-have long been stigmatised ${ }^{18-21}$ and 'connotations of promiscuity, sexual licentiousness and contamination, ${ }^{13}$ pervade. This social pathology has been associated with sex between men with the result that MSM may feel doubly vulnerable in a sexual health setting, an environment where unequal relations are played out. Attending for testing reveals one's private, intimate behaviour, an experience described as uniquely 'anxiety-inducing,' especially for young men and those less open about their sexual conduct. 223 Entering a clinic demands 'the practising of place, the negotiation of intersecting trajectories ${ }^{24}$ where human actions both shape the physical environment and 'human conceptions filter the experience of it. ${ }^{25}$ Particular 'practices' could result in socially awkward interaction and individuals' anonymity being compromised.

Internalised homonegativity ${ }^{12} 18$ may discourage men from disclosing details of their sexual behaviour. In line with other studies, we found that staff had a role in mitigating feelings of stigma associated with sexual health services. ${ }^{11}{ }^{172326}$ Staff were seen as key to managing the anxiety associated with STI testing and in putting patients at ease. However, some participants felt morally judged when asked about partner numbers. It may be that they felt that by asking this question, members of staff were implying that by having many sexual partners, men were responsible for putting themselves at risk of infection. ${ }^{23} 2728$ Professionalism, expertise, friendliness and a non-judgemental attitude were mentioned as valued staff qualities. Participants talked about returning to clinics where they felt comfortable with the procedures and the staff.

We found participants equivocal in their preferences for clinic type with some wanting to consult with a man, or a gay man, in a community setting while others were happy to attend a generic service or GP practice. ${ }^{29} 30$ Some black and ethnic minority men felt vulnerable to community exposure and some had faced disapproval from healthcare professionals from their own communities. ${ }^{31}$

Our findings reinforce those of other studies ${ }^{11} 14$ in acknowledging that attending a sexual health clinic can be an uncomfortable experience but also suggest that, for MSM more familiar with STI testing, attendance becomes normalised and can be a routine practice. In the context of rising STI diagnoses among MSM, service providers should note the impediments to clinic

\section{Key messages}

- STI testing generated anxiety and embarrassment for some men who have sex with men (MSM), especially younger and less experienced men.

- The knowledge, conduct and demeanour of staff in STI testing services could exacerbate or ameliorate unease felt about attendance.

- There is no overwhelming preference among MSM for a specific type of service though generic genito-urinary medicine clinics continue to be the most common choice for STI testing. attendance which can be ameliorated by considering privacy and confidentiality. Staff should be sensitive to men's fears of being judged negatively, especially those unused to being open about their sexuality or sexual practices. Self-sampling and self-testing methods for use in the home present alternatives or access routes to clinical services for those reticent about attendance but do not replace the highly valued face-to-face services provided by clinic staff. $^{32}$

\section{Handling editor Jackie A Cassell}

Acknowledgements We thank the men who participated in the focus groups and to staff at Yorkshire MESMAC, Birmingham LGBT and the LGBT Foundation, Manchester, who facilitated the groups. We acknowledge members of the NIHR HPRU in Blood Borne and Sexually Transmitted Infections Steering Committee: Caroline Sabin, Anthony Nardone, Catherine H Mercer, Gwenda Hughes, Greta Rait, Jackie Cassell, William Rosenberg, Tim Rhodes, Kholoud Porter and Samreen ljaz.

Contributors PW designed and led the study. DR and JD and another member of Sigma staff conducted the FGDs. JD, PW and DR contributed to data analysis. JD prepared the first draft of the manuscript. JD, PW and DR revised the manuscript. All authors commented on and approved the final version of the paper.

Funding The research was funded by the National Institute for Health Research Health Protection Research Unit (NIHR HPRU) in Blood Borne and Sexually Transmitted Infections at UCL in partnership with Public Health England (PHE) and in collaboration with the London School of Hygiene and Tropical Medicine. The views expressed in this publication are those of the authors and not necessarily those of the NHS, the NIHR, the Department of Health or PHE.

Competing interests None declared

Ethics approval The study was approved by LSHTM's ethics committee on 2 June 2015 (ref: 9060) and by the NRES Committee South Central-Oxford C on 3 June 2015 (ref: 15/SC/0223).

Provenance and peer review Not commissioned; externally peer reviewed.

Open Access This is an Open Access article distributed in accordance with the Creative Commons Attribution Non Commercial (CC BY-NC 4.0) license, which permits others to distribute, remix, adapt, build upon this work non-commercially, and license their derivative works on different terms, provided the original work is properly cited and the use is non-commercial. See: http://creativecommons.org/ licenses/by-nc/4.0/

(C) Article author(s) (or their employer(s) unless otherwise stated in the text of the article) 2018. All rights reserved. No commercial use is permitted unless otherwise expressly granted.

\section{REFERENCES}

1 BASHH/MEDFASH. Standards for the management of sexually transmitted infections (STIS, 2014.

2 Clutterbuck D. The BASHH MSM special interest group. Sex Transm Infect 2015;91:538.

3 Mohammed $H$, Mitchell $H$, Sile B, et al. Increase in sexually transmitted infections among men who have sex with men attending sexual health clinics, by patient characteristics, England, 2014. Emerg Infect Dis 2016;22.

4 BASHH. Recommendations for testing for sexually transmitted infections in men who have sex with men, 2014.

5 Skingsley A, Yin Z, Kirwan P, et al; HIV in the UK - Situation Report 2015: data to end 2014. London: Public Health England, 2015.

6 Deblonde J, De Koker P, Hamers FF, et al. Barriers to HIV testing in Europe: a systematic review. Eur J Public Health 2010;20:422-32.

7 de Wit JB, Adam PC. To test or not to test: psychosocial barriers to HIV testing in highincome countries. HIV Med 2008;9 Suppl 2:20-2.

8 Berg RC, Ross MW, Weatherburn P, et al. Structural and environmental factors are associated with internalised homonegativity in men who have sex with men: findings from the european MSM Internet survey (EMIS) in 38 countries. Soc Sci Med 2013;78:61-9

9 Adam PC, de Wit JB, Bourne CP, et al. Promoting regular testing: an examination of HIV and STI testing routines and associated socio-demographic, behavioral and socialcognitive factors among men who have sex with men in New South Wales, Australia. AIDS Behav 2014;18:921-32.

10 Knussen C, Flowers P, McDaid LM, et al. Factors associated with recency of HIV testing amongst men residing in Scotland who have sex with men. AIDS Care 2014;26:297-303.

11 Scoular A, Duncan B, Hart G, et al. "That sort of place where filthy men go:a qualitative study of women's perceptions of genitourinary medicine services. Sex Transm Infect 2001;77:340-3. 
12 Pachankis JE, Hatzenbuehler ML, Hickson F, et al. Hidden from health: structural stigma, sexual orientation concealment, and HIV across 38 countries in the european MSM Internet Survey. AIDS 2015;29:1239-46.

13 Balfe M, Brugha R, O' Connell E, et al. Where do young irish women want Chlamydiascreening services to be set up? A qualitative study employing Goffman's impression management framework. Health Place 2010;16:16-24.

14 Mulholland E, Van Wersch A, Stigma VWA. Stigma, sexually transmitted infections and attendance at the GUM Clinic: an exploratory study with implications for the theory of planned behaviour. J Health Psychol 2007;12:17-31.

15 Cartier C. From home to hospital and back again: economic restructuring, end of life, and the gendered problems of place-switching health services. Soc Sci Med 2003;56:2289-301.

16 Sellman D. Trusting patients, trusting nurses. Nurs Philos 2007:8:28-36.

17 Sonnex C. Empathy: improving the quality of the genitourinary medicine consultation. Int J STD AIDS 2008;19:73-6.

18 Alonzo AA, Reynolds NR. Stigma, HIV and AIDS: an exploration and elaboration of a stigma trajectory. Soc Sci Med 1995;41:303-15.

19 Foley E, Patel R. Destigmatising STIs: remaining challenges, new opportunities. Sex Transm Infect 2001;77:306-7.

20 Hood JE, Friedman AL. Unveiling the hidden epidemic: a review of stigma associated with sexually transmissible infections. Sex Health 2011;8:159-70.

21 Hall L. Venereal diseases and society in Britain, from the Contagious Diseases Acts to the National Health Service. In: Davidson R, Hall L, eds. Sex, sin and suffering: venereal disease and european society since 1870. London Routledge, 2001.
22 Knight R, Small W, Shoveller JA. HIV stigma and the experiences of young men with voluntary and routine HIV testing. Sociol Health IIIn 2016;38:153-67.

23 Worthington C, Myers T. Factors underlying anxiety in HIV testing: risk perceptions, stigma, and the patient-provider power dynamic. Qual Health Res 2003;13:636-55.

24 Massey D. For space. London: Sage, 2005.

25 Rhodes T, Singer M, Bourgois $\mathrm{P}$, et al. The social structural production of HIV risk among injecting drug users. Soc Sci Med 2005;61:1026-44.

26 White G,Mortensen A. Counteracting stigma in sexual health care settings.. The Internet Journal of Advanced Nursing Practice2002;6.

27 Fortenberry JD. The evolving sexual health paradigm: transforming definitions into sexual health practices. AIDS 2013;27 Suppl 1:S127-S33.

28 Knight R, Shoveller JA, Oliffe JL, et al. Heteronormativity hurts everyone: experiences of young men and clinicians with sexually transmitted infection/HIV testing in British Columbia, Canada. Health 2013;17:441-59.

29 Koester KA, Collins SP, Fuller SM, et al. Sexual healthcare preferences among gay and bisexual men: a qualitative study in San Francisco, California. PLoS One 2013;8:e71546.

30 Sonnex C. Destigmatizing genitourinary medicine and sexually transmitted infections in the UK. Int J STD AIDS 2009;20:748-51.

31 Burns FM, Johnson AM, Nazroo J, et al. Missed opportunities for earlier HIV diagnosis within primary and secondary healthcare settings in the UK. AIDS 2008;22:115-22.

32 Paudyal P, Llewellyn C, Lau J, et al. Obtaining self-samples to diagnose curable sexually transmitted infections: a systematic review of patients' experiences. PLoS One 2015;10:e0124310. 